\title{
The Effect of Polyacrylic Ester on Electrochemical Corrosion Behavior of Low-Alloy Steel in Polymer Modified Concrete Exposed to Marine Environment
}

\author{
Guiping Zhao ${ }^{1, *}$, Shiwei $W^{2} n^{2}$ Xiaoming Sun ${ }^{3}$ \\ ${ }^{1}$ School of Civil Engineering, Shandong Polytechnic, Jinan 250104, China \\ ${ }^{2}$ Zhongshan haohui metal Products Co., Ltd, Zhongshan 528400, China \\ ${ }^{3}$ TBEA Shenyang Electric Technology Consulting Co., Ltd. Shenyang 110000, China \\ "E-mail: zgp0629@ sina.com \\ doi: $10.20964 / 2021.08 .35$
}

Received: 17 April 2021/ Accepted: 3 June 2021 / Published: 30 June 2021

\begin{abstract}
In this work, the effects of bagasse ash (BA) and polyacrylic ester (PE) additives on the durability of polymer modified concrete were investigated. Corrosion behavior of low-alloy steel reinforced concrete mixture modified with BA and PE subjected to the marine environment was studied by electrochemical impedance spectroscopy (EIS) and potentiodynamic polarization tests. The PE8 mixture including 8\% $\mathrm{PE}$ had the best corrosion resistance, according to the EIS findings fitted by a suitable equivalent circuit. In comparison to unmodified concrete, polarization analysis showed that PE-modified concretes had more positive corrosion potential, lowest corrosion current density and high corrosion resistance. PE admixtures significantly increased the compressive strength of concrete. The findings of this study show that the efficiency of PE-modified concrete exposed to corrosive environments was higher than unmodified one. PE-modified concrete contributed to low water absorption and considerable resistance to chemical attack.
\end{abstract}

Keywords: Polymer modified concrete; Electrochemical corrosion behavior; Polyacrylic ester; Compressive strengths; Water absorption

\section{$\underline{\text { FULL TEXT }}$}

(C) 2021 The Authors. Published by ESG (www.electrochemsci.org). This article is an open access article distributed under the terms and conditions of the Creative Commons Attribution license (http://creativecommons.org/licenses/by/4.0/). 